\title{
El desvío del surco. Delirio y patologización de la imagen
}

\section{The deviation from the path. Delirium and pathologization of the image}

Jairo Gutiérrez Avendaño*

\section{Resumen}

Esta revisión se deriva del cruce de dos perspectivas: la cultura visual puesta en relación con la cultura psi. En este caso, se refiere al impacto psíquico de las imágenes y su patologización en la cultura. En ese sentido, se aborda el desprestigio de la sensibilidad y la imaginación como origen del concepto clásico de desviación. Los regímenes de visibilidad atravesaron por la instauración de un poder de la imagen durante la "revolución de la fe" cristiana, que se debatió entre la iconoclastia y la legitimación del delirio. Ya en la modernidad, esta se caracterizó por manifestar una hiperestesia de la atención y una supuesta psicosis colectiva, así como la percepción sobre la controvertida "pérdida de la realidad" y los trastornos alucinatorios que, al parecer, se deberían al consumo de estímulos hipersensoriales que moldearían tanto el comportamiento de una sociedad, como su forma de imaginar y representar la vida individual y colectiva.

Palabras clave: Imaginación, desviación, delirio, psicosis, regímenes de visibilidad, crisis de la representación

\begin{abstract}
This paper is derived from crossing two perspectives: the visual culture seen in conjunction with psycultures. In this case, it refers to the psychic impact of the images and their pathologization in the culture. In that sense, the discrediting of the sensitivity and imagination as the source of the classical concept of deviation is discussed. These visibility regimes went through the establishment of a power of the image during the revolution of the Christian faith, who was torn between iconoclasm and legitimacy of delirium. In modernity, this is characterized by manifesting a hyperesthesia of attention and a perceived collective psychosis, as well as the perception on the controversial "loss of reality" and delusional disorder, apparently due to hyper-

* Candidato a Doctor en Ciencias Humanas y Sociales, UNAL-Med. Magíster en Educación, UdeM. Filósofo, UdeA. Integrante del grupo Estudios de Fenómenos Psicosociales, Funlam, Medellín. Correo electrónico: jairo.gutierrezav@amigo.edu.co
\end{abstract}


sensory stimuli consumption that would shape both, a society behavior as its way of picturing and representing individual and collective life.

Keywords: Imagination, deviation, delusion, psychosis, regime of visibility, crisis of representation

\section{Introducción}

Esta revisión se derivó del cruce de dos perspectivas: la cultura visual en relación con la cultura psi; en este caso, se refiere al impacto psíquico de las imágenes y su patologización en la cultura. En ese horizonte, se revisitó el origen clásico de la noción de "desvío" como prevención de la imaginación o mundo de las apariencias que faltaba al principio de verdad, propio del hombre virtuoso idealizado por el mundo griego. La desviación de la razón, como punto de referencia medio para regular la conducta humana fue asumida a lo largo de la historia, con criterios relativamente continuos sobre la aberración, la rebeldía, la inconformidad, entre otras actitudes juzgadas por la filosofía y un primer antecedente de democratización del delirio; asimismo, de su legitimación por parte de la religión en cuanto al enfrentamiento de la idolatría y la iconoclastia; hasta la patologización de la imagen en la vida psíquica de la modernidad.

El proceso civilizatorio, en la primera mitad del siglo $\mathrm{XX}$, estuvo caracterizado por una hiperestesia de la atención (Pedraza, 2011, p. 290), en tanto los individuos estuvieron más expuestos a la impresión de estímulos sensoriales en el espacio público, las fábricas y las escuelas, para aumentar la atención de ciudadanos activos, concentrados y, por tanto, más productivos; de ahí que la desatención fue considerada una anomalía que exigió una cuantificación de la percepción para optimizar la concentración y prevenir la fatiga laboral, escolar y de la movilidad urbana.

En esta época se establecieron dispositivos de higiene mental que hicieron habituales las advertencias peligrosistas sobre el impacto psíquico de la recepción de imágenes y otros contenidos culturales como los libros, el cine y el teatro, en tanto se produjeron supuestos estados de psicosis colectiva, incluso en términos epidémicos, como lo plantea Dan Sperber en su epidemiología de la cultura, dado que las patologías al igual que las representaciones, "algunas se 
transmiten lentamente durante generaciones; son lo que llamamos 'tradiciones' y son comparables a las endemias; otras son típicas de las culturas modernas, se extienden con rapidez por toda una población, pero tienen una vida corta; son lo que llamamos 'modas' y son comparables con las epidemias" (2005, p. 61). En ese sentido, se entenderá el prejuicio del consumo de imágenes como supuesto causante de una psicosis colectiva caracterizada por la crisis de la representación de la realidad o fantasmagoría propia del delirio ${ }^{1}$, entendido como creencia u opinión falsa sobre cosas objetivas que, de acuerdo con Jáuregui \& Méndez, este asume literal la metáfora, elimina el doble sentido de los símbolos, así toma la parte por el todo, la imagen por la realidad, la instala como verdad y vive en función de ella (2009, p. 17).

\section{Desprestigio del mundo sensible como desviación}

Aunque se juzgue de remoto, es imprescindible aludir al mundo griego en el que se inició una larga tradición de la racionalidad occidental para el conocimiento del ser, del cosmos y la naturaleza de las cosas. Este predominio de la razón para acceder a la verdad exigía recorrer dos caminos, como los trazados en el Poema del ser de Parménides al galope de dos corceles que se disputaban el camino que debía seguir el "hombre virtuoso", guiado por la diosa de la verdad (Aletheia). En este se refiere al camino del gnous (del conocimiento inteligible por la razón) y el de la doxa (de la opinión vulgar sensible). De ahí se deriva la noción de paradoxa y la clásica tensión entre la rectitud y el desvío.

Según Jean-Pierre Vernant, esta doctrina señala el advenimiento de "la contradicción entre el devenir del mundo sensible —este mundo jónico de la physis y de la génesis — y las exigencias lógicas del pensamiento" (1993, p. 362). En efecto, estos senderos bifurcados generaron en el proyecto filosófico y político de la academia platónica una ruptura entre el logos (discurso racional) y el mithos (relato de ficción). Es ahí donde inicia un desprestigio de la imaginación por tratarse de una forma que desvirtuaba el modelo o la idea como tal, en tanto artilugio o apariencia de lo real; fenómeno también comentado por Régis Debray (1998) y Michel Melot (2010) en sus trabajos sobre historia de la mirada y de la imagen.

\footnotetext{
1 Delirare significa en latín salirse del surco, del recto camino (de: fuera, lirare: arar, lira: surco). De ahí que implica el desvío de la norma, exceso y esterilidad, salir de la colectividad por la incapacidad del delirante para ser productivo (Huertas, 2014, p. 10).
} 
Este predominio de las ideas por sobre las imágenes y, en general, la instauración de un régimen de racionalidad, se definió como "revolución mental" o "milagro griego" por la preponderancia del contemplar con asombro (miraculum). Es así como, en esta época surge una crítica platónica contra el politeísmo que promovía el culto de deidades míticas, hechas a imagen y semejanza de los hombres. Esta iconoclastia llevó a Sócrates al suicidio por su empeño en rechazar las imágenes como apariencia de verdad.

El delirio considerado enfermedad de la imaginación, se manifestaba como una posesión divina. En el mundo griego esta aparece atribuida a dos espíritus (daimones), que son la manía en oposición a la cordura (sophrosýne), moderación para hacerle frente a la maldad y al espíritu de hybris que desencadenaba el desorden (Vernant, 1992). Según J-P Vernant, "se trataba de un delirio institucionalizado y controlado en el interior del grupo, como puede encontrarse hoy en otras culturas, en América del Sur o en Cuba" (Vernant, 1996, pp. 107-126). De hecho, tiene relación con lo que el autor define como "chamanismo griego".

Aunque se había fundado una tradición que rechazó los supuestos atributos nocivos de la imaginación y de los sentidos, el origen mítico y ritual de la primera filosofía griega, estuvo caracterizado por la invocación y la posesión de fuerzas del espíritu, puesto que "entre el control del alma, su evasión del cuerpo y la ruptura del flujo temporal mediante la rememoración de las vidas anteriores, existe una interdependencia que define lo que ha podido llamarse chamanismo griego..." (Vernant, 1993, p. 351). Aunque el autor precisa que el filósofo no era en sí un chamán —que significa "el que sabe"_, sino aquel que divulgaba los secretos de los chamanes de origen órfico y pitagórico, en tanto "lo que era el privilegio de una personalidad excepcional, él lo extiende a todos estos que piden ingresar en su hermandad" (Vernant, 1993, p. 351). Esta práctica introduce una novedad en el pensamiento occidental, puesto que, según el referido historiador francés, la experiencia individual del chamán, que se asume reencarnado en un hombre de dios, se generaliza en el plano ontológico existencial de los seres humanos bajo la forma de una teoría de la reencarnación o metempsicosis (transmigración de las almas), la cual derivó en la idea de la preexistencia del alma o de la reminiscencia en Platón. 
La moderación se asumía en un ámbito humano de la opinión vulgar sensible, mientras que la locura representaba una elevación inspirada (enthousiasmos) que en el trance o éxtasis conducía a revelaciones incomprensibles para otros. Así, la locura tenía un carácter propio de sabiduría; pero, según Foucault, la locura perdió ese carácter de posesión, a partir de la Ilustración, debido a los ideales de un sujeto racional-normal establecidos por la sociedad burguesa que, por el contrario, la consideró como desposesión de facultades humanas y mentales. De esta forma surge otro tipo de desposeído, el "desheredado de la razón”. Se establece un elitismo del delirio, puesto que si provenía de clase media y alta, era un excéntrico, pero si era pobre, un loco.

Un devenir más originario que el del zôon logon-politikón o animal racional político, según el concepto aristotélico, así como el del zôon symbolon (Cassirer, 1982) -en tanto el símbolo constituye una clave de la naturaleza humana-, se encuentra un inconfeso pariente al lado del sapiens: el homo demens: un animal dotado de sinrazón. Ambos habitan en el mismo dispositivo cerebral de regulación, el neocórtex o prefrontal, en términos de la bioantropología de Edgar Morin:

Se trata de un ser con una afectividad intensa e inestable... un ser invadido por la imaginación, un ser que conoce la existencia de la muerte y que no puede creer en ella, un ser que segrega la magia y el mito, un ser poseído por los espíritus y por los dioses... Y puesto que llamamos locura a la conjunción de la ilusión, la desmesura, la inestabilidad, la incertidumbre entre lo real y lo imaginario, la confusión entre lo objetivo y lo subjetivo, el error y el desorden, nos sentimos compelidos a ver al homo sapiens como homo demens (Morin, 2005, p. 131).

Así pregunta y reflexiona el filósofo francés, ¿cómo es posible que un tema como la locura humana, objeto de meditación de los filósofos de la antigüedad, de los sabios de oriente, de poetas de todas partes, de los moralistas clásicos, de Montaigne, de Pascal, de Rousseau, se haya volatilizado, no sólo en la ideología eufórica del humanismo que justificaba majestuosamente la conquista del mundo por parte del gran sapiens, sino también en el pensamiento de los antropólogos? Al respecto responde: "El racionalismo humanista, que triunfa y expira en la 
etnología de Lucien Lévy-Bruhl, confina el delirio de sapiens a sus primeros pasos sobre la tierra como si se tratara de una debilidad infantil” (Morin, 2005, p. 132).

\section{Poderes de la imagen: iconoclastia y delirio}

La iconoclastia desencadenó, según Michel Melot, una guerra de las imágenes, como la ocurrida en la victoria de León III contra los árabes en las murallas de Constantinopla en el año 717 , atribuida al milagro de la Virgen. Los iconodulos o adoradores de imágenes profanas eran considerados herejes y, por tanto, perseguidos por la Iglesia Bizantina. Asimismo, en términos de Regis Debray, la disputa por el poder icónico constituyó una "revolución de la fe" en la Edad Media. Estos efectos políticos de las imágenes, también fueron estudiados por Serge Gruzinski en el periodo del Barroco americano, durante el siglo XVII, característico por acudir a los poderes milagrosos, alucinatorios y persuasivos de la adoración de imágenes religiosas, autorizadas por la institución clerical, con mayor intensidad las de la Virgen, como ocurrió con la de Guadalupe en el México colonial (Gruzinski, 2003, pp. 160-190). Para que esta imaginería religiosa y política funcionara, los poderes instituidos admitieron que lo sobrenatural y lo cotidiano convivieran, al igual que la alucinación hiciera parte de lo real; porque, así, producía credibilidad y dominio de las representaciones mentales (2003, p. 166).

Uno de los atributos que tiene la iconoclastia, de acuerdo con Gruzinski, es que manifiesta un síntoma de las tensiones, frustraciones y conflictos ocasionados por la secularización y diferenciación que buscaba formar individuos conforme al orden de la "vida cristiana y en policía” establecidos por la colonialidad (2003, p. 165). De esta manera, según el historiador francés, "la imagen barroca contribuye a la elaboración del cuerpo y de la persona modernos" (2003, p. 171). Así, en clave de una historia de las mentalidades y con respecto al impacto de la Inquisición sobre la vida psíquica, Gruzinski sugiere que:

Una antropología de los sentimientos y de las pasiones encontraría aquí material para explorar las formas que adoptan la cólera, la ira, el delirio o la locura, o para seguir los lentos progresos del individualismo. Sea como fuere, consciente de que las más de las veces se enfrenta a lo afectivo, y no a la ideología... (2003, pp. 165-166). 
Con respecto a la responsabilidad que tiene la imagen sobre la modelación de un colectivo existente, dice Melot que el peligro no está en ese deseo de consumir imágenes, porque son indispensables para vivir en sociedad, materializar la comunidad y para el conocimiento humano; el verdadero peligro está en negarse a aceptar que son solo imágenes (2010, pp. 18-19). Aparece, por tanto, un estado delirante y psicótico, que no se reduce a la patología mental, sino que habita en la escena de lo normal. No en vano, de acuerdo con el referido autor francés, es crucial desmitificar las imágenes de sus atribuciones de poder, develar su origen y posicionar sus productores (2010, pp. 18-19).

Por lo tanto, existe un delirio legitimado que es el que se produce en el acto milagroso de un retablo o escultura que no tienen por función ser vistos, sino la virtud que tiene la imagen de interpelar o vigilar a quien se presenta ante ellos. Según estos atributos, la iconoclastia o ir en contra de la idolatría como forma de control de los bienes materiales e inmateriales, era sancionada como locura herética por el poder del clero.

Este antecedente medieval pervive en la religiosidad popular actual y como instrumento de evangelización primordial de la doctrina de la Iglesia. En efecto, guardando las proporciones, el potencial del uso de las imágenes para infundir ideas de fidelización con una marca, producto, o campaña, se remonta a la época de esplendor de la iconografía religiosa en el Renacimiento; de este modo, quien entienda el funcionamiento de la religiosidad de un público objetivo, puede captar su atención recurriendo a su régimen de visibilidad o consumo de imágenes.

\section{Hiperestesia de la atención y psicosis colectiva en la modernidad}

La vida anímica de la modernidad, como la definió Georg Simmel en los primeros años del siglo $\mathrm{XX}$, tiene un fundamento psíquico propio del individuo urbanita: es el "acrecentamiento de la vida nerviosa, estimulado por el rápido ininterrumpido intercambio de impresiones internas y externas" (2001, pp. 375-398). La fijación e imprevisibilidad de las percepciones según la repetición y la diferencia que se presentan en ellas, produce un fenómeno que tiene ecos en el caso de los estudios de la sensorialidad, en particular de la atención que, desde finales del siglo XIX, cobró una crucial importancia por la aparición de un campo social, urbano, psíquico e industrial, cada vez más saturado de estímulos (hiperestesiados), ámbitos en los que se consideró 
la inatención como un peligro y un serio problema de bienestar, concentración y desempeño (Crary, 2008, p. 23).

De acuerdo con Simmel, hacia 1903, la ciudad moderna "crea estas condiciones psicológicas (a cada paso por la calle, con el tempo y las multiplicidades de la vida económica profesional, social), produce ya en los fundamentos sensoriales de la vida anímica, en el quantum de consciencia que esta nos exige a causa de nuestra organización como seres de la diferencia..." (2001, pp. 376-377). En efecto, según Jonathan Crary, la cuantificación de la duración e intensidad de las percepciones fue una de las experimentaciones principales de la ciencia cognitiva a mediados del siglo XIX, en particular los estudios de la postimagen de Johann F. Herbart, quien aseguraba que dichas mediciones mentales permitirían "controlar y determinar la entrada secuencial de las ideas en los espíritus jóvenes y que, más concretamente, tenían el potencial de inculcar ideas morales y disciplinarias" (2008, p. 139). De ahí que, el espacio público, la escuela y el trabajo adquirieron un sentido mensurable y controlado en el tiempo.

Por otro lado, Walter Benjamin, también influido por las ideas de Simmel, consideraba que la reproductibilidad técnica de la imagen podía ocasionar un estado psicótico, en los que, incluso, se asumía que esta misma tecnificación creaba la posibilidad de una catarsis o purga contra tales psicosis masivas, "mediante determinadas películas en las que un desarrollo forzado de fantasías sádicas o alucinaciones masoquistas es capaz de impedir su natural maduración peligrosa entre las masas" (2008, p. 87). Sobre este malestar colectivo atribuido a la reproducción mercantil de imágenes, dice Crary que "lo que normalmente llamamos cine, fotografía o televisión, en realidad son elementos transitorios dentro de una secuencia cada vez más rápida de desplazamientos y obsolescencias que forma parte del funcionamiento delirante de la modernización" (2008, p. 23). A propósito, viene al caso lo que refiere Melot, sobre la intensidad de la apropiación interior de las imágenes, o "encarnación de la pantalla":

$\mathrm{Su}$ interiorización se puede volver trágica. Neurosis y psicosis son con frecuencia enfermedades de la imagen de sí y de los otros. La débil escena constituida por el círculo que retiene a los curiosos en una acera, un proyector, una vitrina, un estrado, un vestido, una nariz postiza o cualquier accesorio, son necesarios para distanciar lo real de la 
imagen, desconectarla, protegerla de su entorno, como la barrera separadora de la arena del circo o al espectador de la locura (2010, p. 57).

Para Daniel Bougnoux, sobre la crisis de la representación, "la reducción de la escena como tal, de palabra, de teatro, de película, es irreductible a la violencia... Es un problema psicológico y sociológico delicado saber de qué manera esas imágenes son percibidas, su impacto según la edad y el nivel social de sus receptores" (2006).

\section{Régimen de visibilidad y cultura psi}

En 1996, la revista October, dirigida por la norteamericana Rosalind Krauss, crítica de arte, envió un cuestionario sobre cultura visual a investigadores relacionados con el estudio de imágenes, historiadores del arte, estudiosos del cine y de la visualidad en general. Las respuestas confirmaron la sospecha inicial de sus autores, planteada en el encabezado de las preguntas, al considerar que el desarrollo de este nuevo campo resultaba desafortunado en tanto servía para los intereses de explotación del capitalismo tardío para aumentar el consumo de los mercados globales:

Si este nuevo paradigma de la imagen fue desarrollado originalmente en la intersección de los discursos psicoanalítico y mediático, ahora ha asumido un rol independiente de medios específicos. Como corolario sugeriríamos que los estudios visuales ayudan de una manera modesta y académica a producir sujetos para la nueva fase del capital globalizado (AAVV, 1996-2003, pp. 83-126).

Según Thomas Dakosta, crítico de historia del arte, la enunciación del concepto de "cultura visual" se atribuye a Michael Baxandall (1972), y retomado por la crítica que le hace Svetlana Alpers, en 1983, en cuanto a que "la cultura visual puede sugerir algunos de los conceptos de la mentalité visual, como es el caso de la cultura popular nacionalista", el Volksgeist, cuyos alcances buscaron influir en los regímenes escópicos de políticas totalitarias (AAVV, 1996-2003, pp. 83126). 
Rosalind Krauss (1996), citada por Keith Moxey, afirma que este nuevo campo de investigación implica que la subjetividad humana esté moldeada por la recepción pasiva de "imágenes incorpóreas", que ya no tienen una representación en el mundo real, fantasmagoría que, como se ha venido mencionando, es crucial tener presente según las alusiones al psicoanálisis y su estudio de las imágenes (AAVV, 1996-2003, pp. 83-126).

Por su parte, Thomas Crow, dentro de su respuesta al cuestionario utiliza la analogía de la filosofía light y del New Age, que han cobrado interés para los "estudios psi" y "cultura mental", puestos en relación con los "estudios visuales" y la "cultura visual", es decir, de forma similar habría un interés por comprender los usos y efectos de las imágenes en la cultura que, de igual forma, podrían cruzarse con su impacto en la vida psíquica (AAVV, 1996-2003, pp. 83-126). Así, se abren perspectivas de investigación sobre la imagen de la locura en el cine, la literatura, el arte, la fotografía, la publicidad de psicofármacos, en fotonovelas de época, etc.

Para Daniel Bougnoux, influido por Debray, una de las justificaciones estéticas de este aligeramiento de la cultura, es que "se propone una experiencia de psicología cognitiva: vaciar el lienzo o el objeto para recargar la mirada que toma conciencia reflexiva de sus propios poderes. La obra contemporánea funciona entonces como acertijo y espejo burlón” (2001, pp. 75-81). De nuevo, un lenguaje psicoanalítico que, no en vano, según el referido filósofo francés, hace alusión al aligeramiento como una ascensión semiótica llamada catarsis, que emerge sobre las superficies de las representaciones, para procurar consuelo, comodidad o purga psicótica, como se mencionó sobre los efectos de la reproductibilidad técnica de la imagen en Benjamin; así como dirá Bougnoux, la función principal de la representación, no solo teatral, "sería la de salvarnos o de purgarnos del terror. Si, desde Aristóteles, esa purga se llama catarsis, sospechamos 'representación catártica' como pleonasmo, o para decirlo con Nietzsche que no hay arte sino solamente medicina" (Bougnoux, 2006).

Para Geoff Waite, la fundación de una disciplina emergente como serían los estudios visuales, es una tarea paradójica, por una serie de premisas entre las que incluye la "para-noia", puesto que existe una paranoia clínica o reactiva y una paranoia creativa y filosófica o activa. Así se refiere al caso de Dalí y de Lacan que estudiaron la producción de una "locura razonada", esto es "un 
delirio de interpretaciones en el que series de imágenes, ideas y acontecimientos se perciben como si tuvieran conexiones casuales o todas estuvieran relacionadas con una idea y son internamente coherentes para el sujeto de la ilusión, aunque sin sentido para el observador externo" (Ades, cit. AAVV, 1996-2003, pp. 119-123).

\section{Imagen síntoma como crisis de la representación}

La comprensión de las imágenes como síntomas se basa en la definición freudiana de los fantasmas sobre los que se configura toda psicosis. Presencia invasiva que trastorna la representación, deslizamiento del síntoma figurativo a la figura pensada en su síntoma. No se trata de un modelo clínico sino crítico, que singulariza, suspende el juicio y es anacrónico; noción que no es ajena en la crítica de la historia del arte de Benjamin y su "imagen dialéctica" frente al carácter sintomático del desvanecimiento del aura en la obra de arte por su reproductibilidad técnica y su pérdida del ritual de transmisión. Para Benjamin, a propósito de la imagen síntoma, gracias a la invención de la cámara "tenemos la experiencia de lo visual inconsciente, del mismo modo en que, gracias al psicoanálisis, la tenemos de lo pulsional inconsciente" (2008, p. 87). Un comentario afín se encuentra en Debray, quien afirma que "cada época tiene un inconsciente visual, foco central de sus percepciones... código figurativo que le impone su denominador común a su arte dominante... La pintura ha sido el psicoanálisis del siglo XVI y el cine el del siglo XX" (1998, p. 223). De hecho, es lo que precisamente dice Benjamin:

Una mirada al psicoanálisis ilustra esa capacidad desde otro lado. En efecto, el cine ha enriquecido nuestro mundo de lo significativo con métodos que pueden ilustrarse con los de la teoría freudiana. Un lapsus en una conversación pasaba más o menos inadvertido hace cincuenta años. Que abriera de pronto una perspectiva de profundidad en una conversación que parecía desenvolverse superficialmente, era algo excepcional. Esto ha cambiado desde la Psicopatología de la vida cotidiana. Se han aislado y vuelto analizables cosas que antes nadaban confundidas en la amplia corriente de lo percibido (2008, p. 85).

Conviene hacer alusión a Serge Tisseron, citado por Melot, sobre los "peligros de la imagen", quien hace una crítica a la semiótica porque esta no cuestiona la relación que tienen las imágenes 
con la realidad física (que ellas representan), pero mediante el análisis de las relaciones que mantienen las imágenes con los seres humanos (su realidad psíquica) (Tisseron, 2003, cit. Melot, 2010).

\section{Conclusión}

A lo largo de la historia, la fantasía y la imaginación cruzaron hasta su era de reproductibilidad técnica con la institución de un mercado de la imagen, que generó la invención de nuevos mitos o metarelatos como la "sociedad del espectáculo" que, según Guy Debord, "no es un conjunto de imágenes, sino una relación social entre personas mediatizada por imágenes" (2009, p. 33). Esta se objetiva cuando la propia vida y una visión del mundo desplazan lo real y pasa a vivirse exclusivamente como imagen o representación. Esta relación está imbricada en la "sociedad de consumo" que, según Baudrillard, se caracteriza por una "pauperización psicológica" atribuida al éxtasis del hommo psico-œeconomicus (2009, p. 67), manifestada en su propio demens y causada por la distorsión entre el crecimiento de las necesidades y los bienes, que ocasiona un desequilibrio social cuando se estimula el deseo de una fantasmagoría o imagen de consumo más que un objeto tangible como tal; así, se produce una crisis de la representación; por ejemplo, en la "psique del consumidor", un electrodoméstico más que su función útil representa comodidad, no se venden productos de aseo sino de "belleza" y, en fin, una cosmética es suplemento o simulacro de una ética (Baudrillard, 2009, pp. 67-68). No se trata de una vuelta al antiguo prejuicio filosófico del mundo de las apariencias, ni de asumir una postura apocalíptica de la imagen, sino de la incidencia que tiene la cultura visual en la cultura y saberes psi, para comprender la percepción y la creencia que determinadas sociedades tienen sobre la supuesta "pérdida de la realidad" y los trastornos alucinatorios, al parecer, atribuidos al consumo de estímulos hipersensoriales que moldearían, tanto el comportamiento de una sociedad, como su forma de imaginar y representar la vida individual y colectiva.

\section{Referencias}

AAVV (1996-2003). Cuestionario sobre cultura visual. En: Estudios Visuales, No. 1, pp. 83-126. 
Ades, Dawn, citado por Salvador Dalí. The tragic mith of Millet's Ángelus: paranoiac-critical interpretation...En: AAVV (1996-2003, pp. 119-123).

Baudrillard, Jean (2009). La sociedad de consumo. Sus mitos, sus estructuras. Madrid: Siglo XXI.

Baxandall, Michael (1972-1981). El ojo de la época. En: Pintura y vida cotidiana en el Renacimiento. Arte y experiencia en el Quattrocento, Barcelona: Gustavo Gili.

Benjamin, Walter (2008). La obra de arte en la era de la reproductibilidad técnica. Madrid: Abada.

Bougnoux, Daniel (2006). La crisis de la representación. Paris: La Découverte (Trad. Jorge Márquez V.)

is more”, Strategies du Moins... pp. 75-81. (Trad. Jorge Márquez V.)

Cassirer, Ernst (1982). Antropología filosófica. México: Fondo de Cultura Económica.

Crary, Jonathan (2008). Suspensiones de la percepción. Atención, espectáculo y cultura moderna.

Madrid: Akal, p. 23.

(2008). Las técnicas del observador. Visión y modernidad en el siglo XIX. Murcia:

CENDEAC, 2008, pp. 139.

Debord, Guy (2009). La sociedad del espectáculo. Valencia: Pre-Textos, pp. 33-60.

Debray, Régis (1998). Vida y muerte de la imagen. Historia de la mirada en Occidente. Barcelona: Paidós.

Gruzinski, Serge (2003). Los consumidores de imágenes. En: La guerra de las imágenes. De Cristóbal Colón a "Blade Runner” (1492-2019). México: FCE, pp. 160-198.

Huertas, Rafael (2014). La locura. Colección ¿Qué sabemos de? Madrid: CSIC.

Jáuregui, I. \& Méndez, Pablo (2009). Modernidad y delirio. Ciencia, nación y mercado como escenario de la locura. Madrid: Ediciones Escalera.

Krauss, Rosalind (1996). Welcome to the cultural revolution. In: October, no. 77, p. 85. Cit: Moxey, Keith (1996-2003). La nostalgia de lo real. La problemática relación de la historia del arte con los estudios visuales. En: Estudios Visuales, No. 1.

Melot, Michel (2010). Breve historia de la imagen. Madrid: Siruela.

Morin, Edgar (2005). El paradigma perdido. Ensayo de bioantropología. Barcelona: Kairós. 
Pedraza, Zandra (2011). En cuerpo y alma. Visiones del progreso y de la felicidad. Educación, cuerpo y orden social en Colombia (1830-1990). Bogotá: Universidad de los Andes.

Simmel, Georg (2001). El individuo y la libertad. Ensayos de crítica de la cultura. Barcelona: Península, pp. 375-398

Tisseron, Serge (2003). Le bonheur dans l'image (la felicidad en la imagen). París: Les empêcheurs de penser en rond.

Vernant, Jean-Pierre (1993). Mito y pensamiento en la Grecia antigua. España: Ariel, p. 362. (1992). Los orígenes del pensamiento griego. Barcelona: Paidós, 1992.

(1996). Salud mental y cultura (Entrevista, 1995). En: Revista de la Asociación Española de Neuropsiquiatría, Vol. 16, No. 57, pp. 107-126. 